\title{
Addressing the digital skills gap for future education
}

\author{
The COVID-19 pandemic has caused rushed digitalization of primary and secondary (K12) student education, and \\ cyber-risks such as bullying, technology addiction, and misinformation must be addressed. There is an urgent need \\ to coordinate global efforts for digital skills education and training, which can help students succeed in the digital \\ age while curbing risks and inequality.
}

\section{Joshua A. Jackman, Douglas A. Gentile, Nam-Joon Cho and Yuhyun Park}

$\mathrm{T}$ he digital world is an indelible part of modern life. For many people, it is the world where we communicate, learn, shop, and entertain ourselves. The digital world has transformative power to connect people across the world.

Nonetheless, the digital world has many challenges. It is associated with a wide range of cyber-threats such as hacking, bullying, identity theft, human trafficking, technology addiction, and privacy invasion, while gaming disorder has been recognized as a medical condition by the World Health Organization (WHO).

The ongoing COVID-19 pandemic has accelerated the widespread digitalization of numerous sectors that were unprepared. One of the most affected groups has been K12 students, many of whom have been forced to switch to online schooling. The rapid transition has been challenging and compounded by issues such as limited digital skills, technology access, inequality, and systemic racism.

We urgently need a globally coordinated response to help students acquire digital skills, which are needed to keep pace with this fast-changing landscape. It is especially important to cultivate digital citizenship along with a broader set of digital skills that can facilitate participation and support students in maximizing opportunities and minimizing risks in the digital world.

\section{Cyber-risk impacts}

The impact of the digital world on students began long before the COVID-19 pandemic. The digital world has brought tremendous benefits, but the rate of digital technology advances is far greater than the speed at which we have adapted in terms of education, policies, and culture.

This mismatch has allowed cyber-risks to proliferate among children who are left exposed without adequate preparation or safeguards. To understand the prevalence of cyber-risks worldwide, our team conducted a survey of over 145,000 children and adolescents across 30 countries $^{1}$. The participants were asked questions about their personal experiences with different types of cyber-risks and evaluation metrics were developed based on the frequency of exposure.

Among the survey results, it was found that $60 \%$ of 8 - to 12 -year-old children were exposed to cyber-risks such as cyberbullying, gaming disorder, sexual grooming, and violence (Fig. 1a). Notably, $45 \%$ of children online were affected by cyberbullying, 39\% experienced reputational risks, $29 \%$ were exposed to violent and sexual content, $28 \%$ experienced cyber threats, $17 \%$ had risky contacts such as an offline meeting with strangers or sexual contact, $13 \%$ were at risk of a gaming disorder, and $7 \%$ were at risk of a social media disorder.

The results also showed that countries varied greatly in critical aspects of digital safety and infrastructure (Fig. 1b). East Asian and Western countries tended to rank higher for child online safety. East Asian countries also tended to score high on cyber-risk prevention, disciplined digital use, digital citizenship, and digital connectivity. On the other hand, Western countries tended to have strong social infrastructure, guidance, and education. These data highlight that nations in all regions of the world have room for improvement and could learn from each other's best practices-an issue which has gained heightened attention due to COVID-19.

\section{An educational crisis}

Over the past year, the global K12 education system has largely moved online, which has influenced student learning performance and wellbeing. Indeed, school closures caused by COVID-19 are estimated to have affected up to over $84 \%$ of the world's student population and continue in many locations worldwide ${ }^{2}$.
As a stopgap measure, many schools started using digital education tools to offer online teaching while students stay at home. These efforts have helped students and teachers interact in a physically safe manner and also spurred renewed interest in educational technology innovation. However, there have been concerns about introducing new forms of digital education so abruptly, especially in terms of learning effectiveness and cybersecurity ${ }^{3}$. Such challenges will likely be addressed over time as school systems, teachers, and students become more familiar with the digital learning environment and online teaching approaches are refined.

Of more immediate concern, the switch to online learning has also deepened the exposure of students to cyber-risks and affected socialization ${ }^{4}$. Online classes are leading students to grow accustomed to spending more time online, blurring the distinction between physical and digital spaces. For example, it has been estimated that children are spending around twice as much time on social media sites and video-sharing platforms as compared to the previous year, and increased screen time is associated with technology addiction and mental health effects ${ }^{5-7}$. In addition to technology addiction, there has also been a rise in cyberbullying that coincides with school closures and the switch to online learning $^{8,9}$.

It is imperative to address these growing cyber-risk issues. Even before COVID-19, most students were already suffering from inadequate online safety support and were unprepared to study primarily in the digital world. COVID-19 is a trigger to enact change and help students acquire critically needed digital skills.

\section{Digital skills education}

To date, there have been extensive efforts to create digital skills education programs. The Organisation for Economic Cooperation 
Global monitoring of children's cyber-risk exposure levels $60 \%$ of $8-12$ year-old children online are exposed to cyber risks today

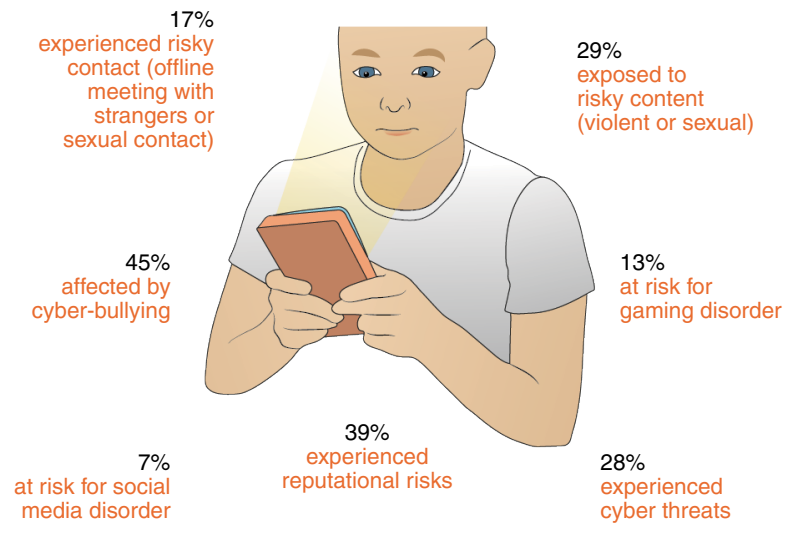

b

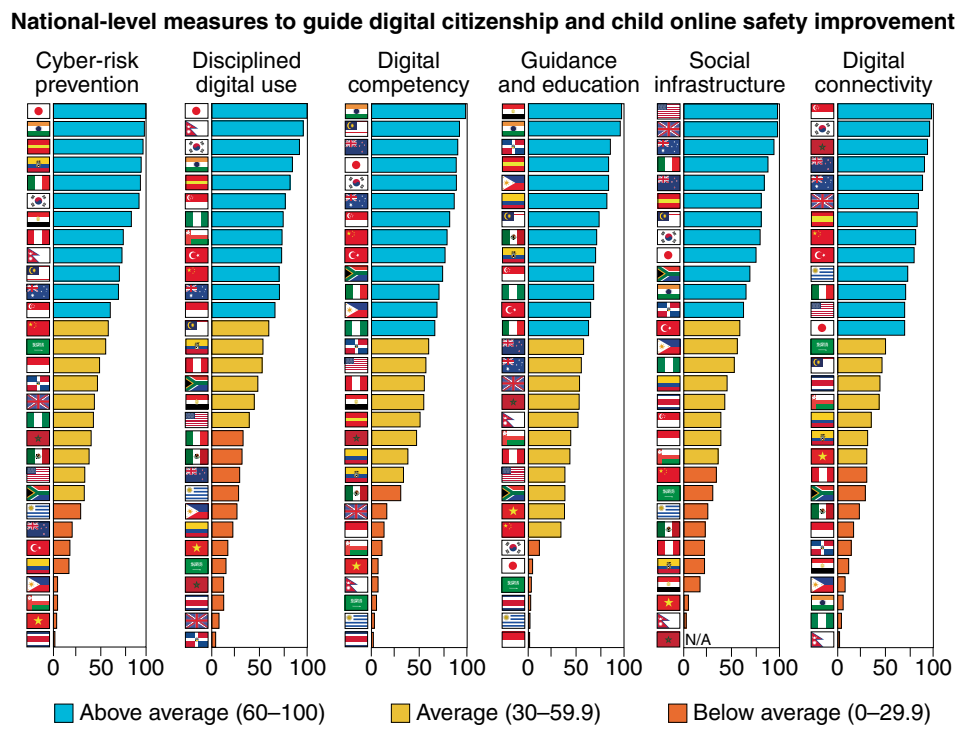

Fig. 1 | Results summary of the Child Online Safety Index. a, Percentages of 8- to 12-year-old children in the survey who reported encountering different types of cyber-risks. b, National comparisons in six different assessment categories: cyber-risk prevention, disciplined digital use, digital citizenship, guidance and education, social infrastructure, and digital connectivity. The scores were standardized across the 30 countries included in the Child Online Safety Index, with higher scores indicating better performance. Adapted with permission from ref. ${ }^{1}$, DQ Institute.

and Development (OECD) Learning Framework 2030 cites digital literacy as a core fundamental competency for future education $^{10}$. However, until recently, there was weak coordination between programs and no globally accepted meaning of concepts such as digital literacy. Hence, the impact of digital skills education programs was limited even while the digitalization of K12 student education accelerates.

To address this issue, the Coalition for Digital Intelligence-comprising the OECD, IEEE Standards Association, and DQ Institute, in association with the World Economic Forum - spearheaded development of the recently approved IEEE Standard for Digital Intelligence (DQ) Framework for Digital Literacy, Skills, and Readiness (3527.1-2020). This set of internationally accepted standards establishes a common framework to coordinate digital-competency-building efforts worldwide.

These global standards build on the emerging concept of the DQ framework, which describes the collective set of technical, cognitive, meta-cognitive, and socio-emotional competencies that can help individuals thrive in the digital world ${ }^{1}$. While digital intelligence has been previously discussed in terms of human interactions with digital technology ${ }^{11}$ and incorporating digital technology into business strategies $^{12}$, the $\mathrm{DQ}$ framework focuses on digital skills education across eight competencies, including identity, use, safety, security, emotional intelligence, literacy, communication, and rights, and across three levels of citizenship, creativity, and competitiveness ${ }^{13}$. It was first described in a World Economic Forum article ${ }^{14}$ followed by a DQ Institute white paper in 2017 (ref. ${ }^{15}$ ).

The DQ framework has been used within the \#DQEveryChild digital citizenship educational program to strengthen fundamental digital skills (the first level of the DQ framework) in over 1 million children in more than 80 countries $^{1}$ (Fig. 2). The program was centred on the DQ World online learning platform, and evaluation of student learning outcomes demonstrated that the competencies are learnable using this program. Numerous government agencies, non-profit organizations, and schools have begun adopting the DQ framework, as demonstrated by successful case study examples in various countries such as Mexico, Turkey, and Thailand.

The \#DQEveryChild program set an important precedent for enhancing digital skills among students, and we believe that the greatest potential of the $\mathrm{DQ}$ framework lies in fostering an innovation ecosystem in which different stakeholders can work together to build and deploy a wide range of digital skills education and training programs that are tailored to specific needs and learning objectives. The newly launched 1 Billion Digital Skills Project, led by the Coalition for Digital Intelligence, embodies this vision and is a call to action for committed stakeholders to work together to empower 1 billion people, especially K12 students, teachers, and parents, with digital skills within 10 years. The project is built on the belief that digital intelligence is a universal human right and can enable the sustainable development of nations with more inclusive growth, wellbeing, and prosperity. To achieve this goal, the project seeks to bring together various stakeholders such as content developers, initiative leaders, academic researchers, and educators to achieve the following objectives:

1. Build a global network of partners that are committed to developing and implementing digital skills education and training programs based on the DQ global standards and to inspiring cooperation. A recent example is the new partnership between the DQ Institute, Alannah \& Madeline Foundation, and Accenture to enable 11- to 14-year-old children in Australia and New Zealand to earn an eSmart Digital Licence that is based on Accenture's Skills to Succeed and incorporates the eight competencies of the DQ framework.

2. Develop a program certification system to evaluate digital skills programs and drive alignment with DQ global 


\section{\#DQEveryChild \\ 2010-2020 \\ Global Outreach}

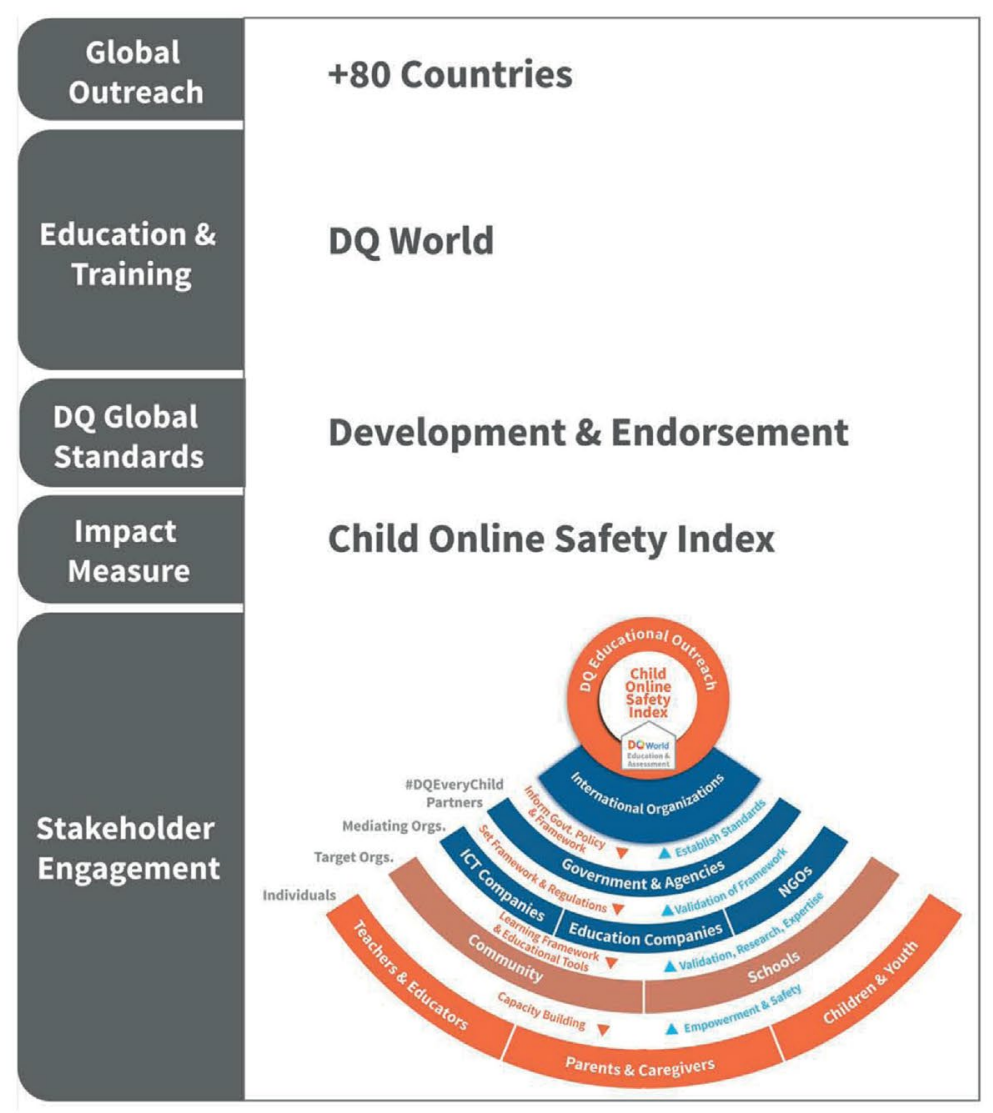

1 Billion Digital Skills

2021 -

Global Standards \& Coordination

\section{All Countries}

Digital Skills Programs Aligned with DQ Global Standards

(IEEE 3527.1)

+ Globally Accepted Certification

+ Common Assessment

\section{Adoption \& Co-Creation}

\section{Global Digital Skills Index}

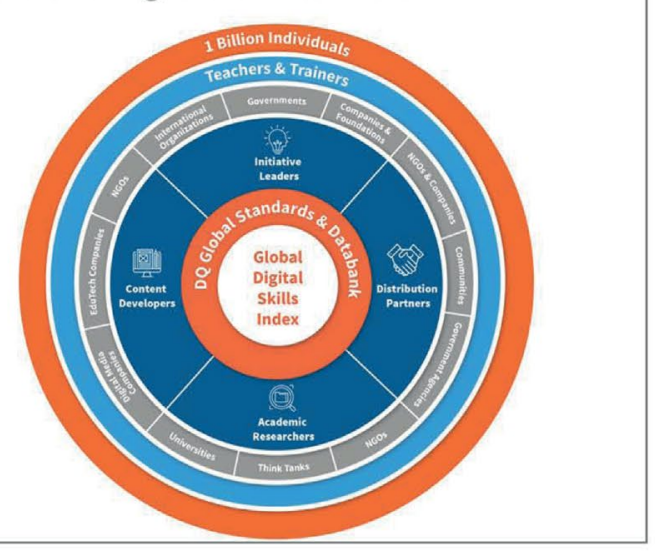

Fig. 2 | Overview of 1 Billion Digital Skills project. Over the past decade, the \#DQEveryChild educational outreach program was implemented to empower K12 students with digital skills based on the DQ framework. The 1 Billion Digital Skills project is a new call to action for stakeholders to adopt DQ global standards and to co-create a wide range of digital skills education and training programs that address societal needs.

standards. This system will provide information about what types of competencies are taught in different programs to guide curriculum planning.

3. Develop microbadge credits that students can earn when they complete learning objectives within certified digital skills programs. The credits can incentivize learning and provide evidence of learning accomplishments, and such approaches can also be extended to teacher training and parent awareness.

4. Create an online assessment platform where individuals and organizations can measure digital skill levels across competencies based on microbadge credits. The results can provide guidance for developing globally accepted performance standards to evaluate digital skills education and training outcomes as well as to measure the impact of specific initiatives.
5. Support ongoing improvement of the DQ global standards based on performance outcomes, student and teacher feedback, stakeholder input, and academic research. Further conceptual development of the DQ framework and quotient will strengthen the pedagogy of digital skills education and training programs. There is also a need to develop rigorous methods for evaluating the educational efficacy of different programs to achieve specific learning objectives. Such feedback can also be used to improve programs and to identify best practices within the DQ framework.

\section{Conclusions and outlook}

The widespread digitalization of the educational sector is happening now, and we must ensure that this transformation occurs inclusively while stemming the tide of rising inequality. Such outcomes would go a long way towards ensuring sustainable development of the digital economy and its potential to transform the lives of countless individuals through digital skills education. We believe that online learning will play an increasingly important role in the K12 education system. We must do more to support student success in the digital world, and these efforts should focus on empowering students with a core set of digital skills. The digitalization of the education sector is the latest example of broader trends in the global economy as a whole and the efforts we describe here can also be applied to teacher training as well as to workforce training in general. Online and offline options are no longer dichotomies; the digital world is becoming increasingly fused into our daily lives and we must make a concerted effort to ensure that all individuals are supported with digital 
skills education and training to thrive in this digital age.

Joshua A. Jackman (D) 1,2,

Douglas A. Gentile (D)1,3, Nam-Joon Cho (D) 4

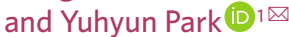

${ }^{1} D Q$ Institute, Singapore, Singapore. ${ }^{2}$ School of Chemical Engineering, Sungkyunkwan University, Suwon, Republic of Korea. ${ }^{3}$ Department of Psychology, Iowa State University, Ames, IA, USA. ${ }^{4}$ School of Materials Science and Engineering, Nanyang Technological University, Singapore, Singapore.

$凶_{e-m a i l: p a r k @ d q i n s t i t u t e . o r g}$

Published online: 11 March 2021

https://doi.org/10.1038/s41562-021-01074-Z
References

1. Child Online Safety Index. A Findings and Methodology Report. https://www.dqinstitute.org/wp-content/uploads/2020/02/20 20-COSI-Findings-and-Methodology-Report.pdf (DQ Institute, 2020).

2. Education: From Disruption to Recovery. https://en.unesco.org/ covid19/educationresponse (UNESCO, 2020).

3. Reimers, F.M. \& Schleicher, A. Schooling Disrupted, Schooling Rethought: How the COVID-19 Pandemic Is Changing Education (OECD, 2020).

4. Colao, A. et al. Lancet Public Health 5, e370 (2020).

5. Dong, H., Yang, F., Lu, X. \& Hao, W. Front. Psychiatry 11, 00751 (2020).

6. Gupta, S. \& Jawanda, M. K. Acta Paediatr. 109, 2181-2183 (2020).

7. Gentile, D. A. et al. Pediatrics 140, S81-S85 (2017). Suppl 2.

8. Karmakar, S. \& Sanchari, D. Proc. Eur. Interdiscip. Cybersecur. Conf., https://doi.org/10.1145/3424954.3424960 (2020).

9. Jain, O., Gupta, M., Satam, S. \& Panda, S. Comput. Hum. Behav. Rep. https://doi.org/10.1016/j.chbr.2020.100029 (2020).

10. The Future of Education and Skills. Education 2030. https:// www.oecd.org/education/2030/E2030\%20Position\%20Paper\%20 (05.04.2018).pdf (OECD, 2020).
11. Adams, N. B. J. Technol. Stud. 30, 93-97 (2004).

12. Mithas, S. \& McFarlan, F. W. IT Prof. 19, 3-6 (2017).

13. Singh Chawla, D. Nature 562, S15-S16 (2018).

4. Park, Y. 8 Digital Skills We Must Teach Our Children.

https://www.weforum.org/agenda/2016/06/8-digital-skills -we-must-teach-our-children/ (World Economic Forum, 2016). 15. Digital Intelligence (DQ). A Conceptual Framework \&

Methodology for Teaching and Measuring Digital Citizenship. https://www.dqinstitute.org/wp-content/uploads/2017/08/ DQ-Framework-White-Paper-Ver1-31Aug17.pdf (DQ Institute, 2017)

Competing interests

Y.P. is the founder and an employee of the DQ Institute, an international think-tank dedicated to setting global standards for digital intelligence education, outreach, and policies. J.A.J., D.A.G., and N.-J.C. are advisors to the DQ Institute.

Additional information

Peer review information Nature Human Behaviour thanks Judy Robertson and the other, anonymous, reviewer(s) for their contribution to the peer review of this work. 